\title{
Towards traffic situation noise emission models
}

2

3

4

7 Ghent University

99000 GENT,

10 Belgium

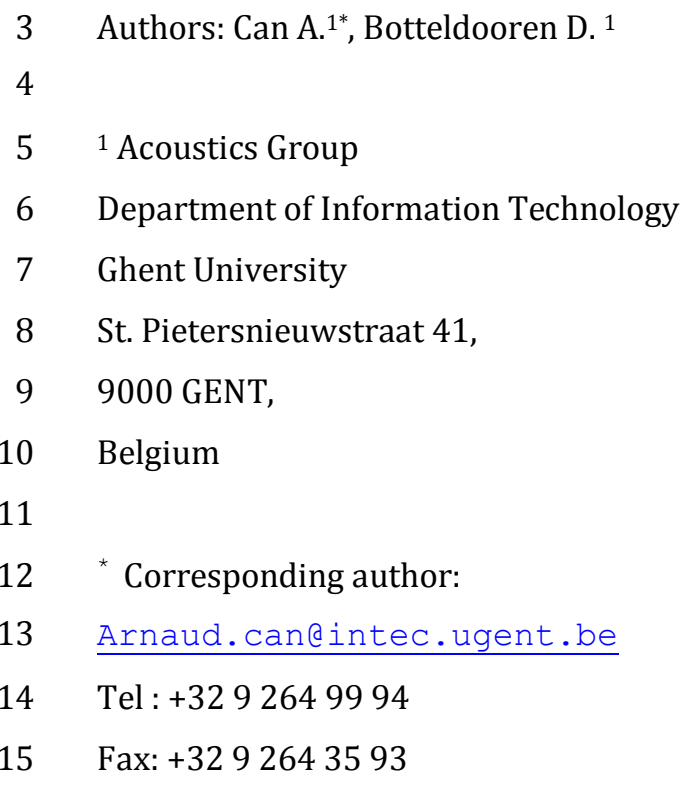

$5 \quad{ }^{1}$ Acoustics Group

6 Department of Information Technology

8 St. Pietersnieuwstraat 41,

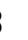

\begin{abstract}
This article proposes a methodology to account for vehicle kinematics in a fast and efficient way when using single vehicle noise emission models such as the Harmonoise/Imagine, Nord2000 or NMPB. A model is built, which mimics the traffic situation emission models developed in the field of airborne pollutants research. The model aggregates the sound power emitted over driving cycles which are statistically representative of real-world driving conditions. Four different driving conditions are included in the cycles, ranging from free-flowing to stop-and-go traffic conditions. The sound power levels estimated with this new approach are significantly different from the ones estimated with the mean speed approach recommended by the noise mapping guidelines, especially when traffic is congested, suggesting that the method could prove relevant for improving noise map accuracy, in particular in urban context.
\end{abstract}


Noise mapping is a crucial tool to communicate on sound levels exposure, and is mandatory in Europe for main road and rail infrastructures and for cities of more than 250,000 inhabitants [1]. Concerning road traffic noise, most of the modern standard methods (Harmonoise/Imagine, Nord2000, NMPB, etc.) separate emission from propagation [2][3][4]. Noise emission models usually give the sound power level emitted by a single vehicle as a function of its instantaneous speed and acceleration. The main practical issue when computing a noise map is then the difficulty to collect accurate vehicle speed data. Indeed, inaccuracies in mean speeds yield to discrepancies in sound level and sound spectrum estimations [5][6]. If accurate speed distributions are not available, the European good practice guide recommends using the speed limit or accurate average speeds measurements as an input for noise emission models, to compute noise maps [7]. Even when speed distributions are known vehicle accelerations and idle time are extremely rarely available and thus taken into account.

Interestingly, the research on exposure to airborne pollutant has led to the development of traffic situation models. Those models provide emission factors, which consist in amount of pollutants (in $\mathrm{g} / \mathrm{km}$ ) emitted for predefined traffic situations. The traffic situations are described by the road type, speed limit, and traffic condition. Here the vehicle kinematics is implicitly taken into account, as the emission factors are determined from driving cycles, which are constructed to be statistically representative of the driving conditions encountered for each traffic situation.

The purpose of this article is to show the interest of copying this approach to build noise emission models that implicitly take vehicle kinematics into account. A model which aggregates the traffic situations found in the pollutant emission model ARTEMIS is built. The model Harmonoise/Imagine is used to calculate road traffic noise emission factors. Outputs of the new model are then compared to noise emissions estimated with the speed limit and average speed approaches. Finally, required further works needed to generalize this approach are underlined in the conclusion.

\section{Method}

\section{II.1 Noise emission model Harmonoise/Imagine}

The noise emission model Harmonoise/Imagine gives the sound power level emitted by a vehicle representative of an averaged European vehicle fleet, as a function of its speed and acceleration [2]. Several vehicle classes are defined: two-wheelers, light vehicles, buses, heavy trucks, etc. However, only light vehicles will be considered in this paper. Sound power levels are expressed per $1 / 3$ octave band, as the sum of rolling noise $L_{\text {rol }}$ and propulsion noise $L_{\text {prop }}$. Two sources are considered for light vehicles to represent both rolling and propulsion noise: the lowest source is located at $0,01 \mathrm{~m}$ above the road, and the highest source is located at $0,3 \mathrm{~m}$. $80 \%$ of the rolling noise is attributed to the lowest source, $20 \%$ to the higher source and vice versa for the propulsion noise. Equations and coefficients proposed in [2] are used 
in this paper. They correspond to a virtual reference road surface, consisting of a mixture of Dense Alphalt Concrete DAC 0/11 and Stone Mastic Asphalt SMA 0/11.

\section{II.2 Traffic situation model ARTEMIS}

Traffic situation models have been developed to make airborne pollutant emission inventories. Their aim is to determine the amount of pollutants (in $\mathrm{g} / \mathrm{km}$ ) emitted by a car evolving on a road segment under a given traffic condition. The input required to build inventories is, for each road link, the vehicle kilometers travelled under each traffic condition. The European traffic situation model ARTEMIS will be considered in this paper [8]. This model classifies road links into a traffic situation scheme that takes into account their area (Urban or Rural), their road type according to a functional hierarchy (Local, City Motorway, etc.), their speed limit, and their driving condition (free flow, heavy, saturated, and stop-andgo), for a total amount of 276 different traffic situations.

The core of the model consists of the real-world driving cycles, which have been built for each of those traffic situations. Each cycle consists of the speed evolution with time over a few hundred seconds, and is assumed to be statistically representative of the traffic conditions experienced by the vehicle in this traffic situation. Thus, a small proportion of low speeds are also encountered within free flowing cycles, due to speed variations close to entrances of the roads. Cycles have been built after on-road measurements operated on 77 monitored vehicles which covered a global distance of $88,000 \mathrm{~km}$, by means of correspondence analysis and clustering tools [9]. Emission factors are calculated in $(\mathrm{g} / \mathrm{km})$ for an average fleet of vehicles over those cycles.

\section{II.3 Traffic situation noise emission model}

This paper focuses on 44 traffic situations commonly encountered in urban area. Covered traffic situations are summarized in Table 1.

The procedure followed to build the noise emission model that takes traffic situation into account is similar to the ARTEMIS approach. It is illustrated in Figure 1 for the two following traffic situations: i) City motorway road with $70 \mathrm{~km} / \mathrm{h}$ speed limit under free flowing traffic condition, ii) Local urban road with $50 \mathrm{~km} / \mathrm{h}$ speed limit under saturated traffic flowing condition. Figure $1 \mathrm{a}, \mathrm{b}$ show speed as a function of time for both traffic cycles. The driving cycle ii, which is driven under saturated traffic flowing condition, has an average speed $V_{\text {mean }}$ far below the speed limit $V_{\text {limit. }}$ Assuming a mean speed of $V_{\text {limit }}$ when building noise maps would thus result in an overestimation of noise levels for this traffic situation. The Figure 1c,d show $L_{\mathrm{w}, \mathrm{A}}$ as a function of time over the driving cycles, computed with Harmonoise/Imagine from the instantaneous speeds and accelerations, rolling and propulsion noise combined. The $L_{\mathrm{w}, \mathrm{A}}$ (cycle), calculated over the whole cycle, will be statistically representative of the sound power level emitted by a vehicle evolving on this road segment, under this traffic situation. The Table 2 compares the amount of rolling and propulsion noise for both cycles that corresponds to $V_{\text {limit }} V_{\text {mean }}$, and calculated over the whole cycles. Instantaneous sound power levels averaged over the cycle are given. Note that values 
corresponding to $V_{\text {limit }}$ are corrected by $10^{*} \log 10\left(V_{\text {cycle }} / V_{\text {limit }}\right)$ to take into account the difference in trip duration. The Table 2 reveals that the difference in sound power levels emitted is mainly due to rolling noise, which varies more than propulsion noise between 20 and $70 \mathrm{~km} / \mathrm{h}[2]$.

\section{Results}

The Figure 2a depicts the traffic situation noise emission model obtained by calculating the A-weighted sound power level $L_{\mathrm{w}, \mathrm{A}}$ corresponding to each ARTEMIS driving cycle. $L_{\mathrm{w}, \mathrm{A}}$ values are obtained as follows: A-weighted sound powers per meter road segment (expressed in $\mathrm{W} / \mathrm{m}$ ) are first calculated, and then converted into A-weighted sound power levels. This allows for the comparison with the average speed methods, which directly deduces emissions from speed limits or average speeds. It should be read as follows: on a City Motorway where speed limit is $70 \mathrm{~km} / \mathrm{h}$, under free flowing conditions, one can assume vehicle kinematics to be statistically distributed on the road link such as the global emitted sound power level is $87 \mathrm{~dB}(\mathrm{~A})$. The correlation between driving cycle and position along the road is thus ignored, which implies that the local effect of road crossings, pedestrian crossing, etc., cannot be estimated with the proposed approach. Note that alternative methods have been developed in the past to refine estimations close to intersections [10].

Large discrepancies can be observed between the estimates resulting from assuming that all cars drive at the speed limit and the estimates taking the whole driving cycle into consideration. In particular, the difference can reach $8 \mathrm{~dB}(\mathrm{~A})$ under saturated and stop-and-go conditions, mainly because the real driving speeds are far below speed limit (Figure 2a). The Figure 2c, which depicts the averaged speed over each driving cycle in terms of speed limit, illustrates this explanation. In particular, saturated and stop-and-go conditions lead to average speeds that do not exceed $30 \mathrm{~km} / \mathrm{h}$, independently of the speed limit.

The Figure $2 \mathrm{~b}$ represents the traffic situation noise emission model in terms of the average speed of the driving cycle, which compares the sound power levels predicted when accurate average speeds are known, to the ones predicted when driving cycles are used. Results show smaller differences between the two approaches than when speed limits were used. Nevertheless, as underlines the Figure $2 \mathrm{~d}$, the average speed approach leads to an underestimation of noise emissions. In particular, under saturated and stopand-go conditions, the non-consideration of vehicle kinematics (mainly acceleration phases and speed distribution), which are taken into account by the cycles, leads to the underestimations of noise levels emitted by up to $4 \mathrm{~dB}(\mathrm{~A})$.

\section{Conclusions}

Due to the lack of detailed traffic flow information, current practice in noise mapping often relies on speed limits or (calculated) average vehicle speed to calculate vehicle noise emission. Several European noise emission standards (Nord2000, Harmonoise/Imagine, NMPB) are based on individual vehicle speed and acceleration. Hence we propose a fast and efficient method to obtain more realistic noise emission implicitly including speed and acceleration - that is based on a rough street categorization: their area 
(Urban or Rural), their road type according to a functional hierarchy (Local, City Motorway, etc.), their speed limit, and their driving condition (free flow, heavy, saturated, and stop-and-go). The proposed method considers emissions over driving cycles that are statistically representative of real on-road driving conditions. It is illustrated that very significant differences can be expected compared to simply using speed limits (up to $8 \mathrm{~dB}(\mathrm{~A})$ for stop-and-go traffic). The difference compared to using average speed is more moderate but still an underestimation of $4 \mathrm{~dB}(\mathrm{~A})$ can be expected for saturated and stop-and-go driving conditions.

Nevertheless, some weaknesses remain by mimicking the approach developed in the airborne pollutants field of research. Mainly, the driving cycles developed for pollutant emission estimation are not necessarily coherent with the spatial accuracy required for noise estimation, since their concern is global inventories. Hence, the approach proposed shows limits to assess noise levels under some specific urban traffic situations, such as road segments with traffic signal synchronization, noise estimation close to intersections, etc. It could thus be interesting as a further work to build driving cycles dedicated for noise estimation, by selecting relevant noise traffic situations.

\section{Acknowledgement}

The support of the Research Foundation-Flanders (FWO-Vlaanderen) for this research is gratefully acknowledged.

\section{References}

[1] Directive 2002/49/EC of the European Parliament and of the Council of 25 June 2002, relating to the assessment and management of environmental noise. Official Journal of the European Communities, 2002.

[2] B. Peeters, G. v. Bokland: The noise emission model for European road traffic. Technical report IMA55TR-060821-MP10, Deliverable 11 of the IMAGINE project: Improved Methods for the Assessment of the Generic Impact of Noise in the Environment, 2007.

[3] J. Kragh, H. Jonasson, B. Plovsing, A. Sarinen. User's Guide Nord2000 Road, 2006.

[4] J.F. Hamet, F. Besnard, S. Doisy, J. Lelong, E. LeDuc: New vehicle noise emission for French traffic noise prediction. Applied Acoustics 71 (2010) 861-869.

[5] G. Watts, D. van Maercke, H. van Leeuwen, R. Barelds, M. Beuving, J. Defrance, H. Jonasson, R. Nota, G. Taraldsen, J. Witte: Effects of speed distributions on the Harmonoise model predictions. 
Proceedings of the 33rd International Congress and Exposition on Noise Control Engineering, Prague, Czech Republic, August 22-25, 2004.

[6] A. Can, L. Leclercq, J. Lelong, D. Botteldooren: Traffic noise spectrum analysis: Dynamic modeling vs. experimental observations. Applied Acoustics 71 (2010) 764-770.

[7] European Commission. Working Group Assessment of Exposure to Noise (WG-AEN). Position Paper. Good Practice Guide for Strategic Noise Mapping and the Production of Associated Data on Noise Exposure - Version 2 - 13th January 2006.

[8] P. Boutler, I. McCrae: ARTEMIS: Assessment and reliability of transport emission models and inventory systems - Final Report, Deliverable 15 of the ARTEMIS Project, Workpackage 1300: Final Report and Dissemination, 2007.

[9] M. André: The ARTEMIS European driving cycles for measuring car pollutant emissions. Science of the Total Environment 334- 335 (2004) 73-84.

[10] B. De Coensel, D. Botteldooren, F. Vanhove, S. Logghen: Microsimulation Based Corrections on the Road Traffic Noise Emission near Intersections. Acta acustica united with acustica 93 (2007) 241252. 


\begin{tabular}{|c|c|c|c|c|c|c|c|c|c|c|c|}
\cline { 4 - 12 } Area & Road Type & $\begin{array}{c}\text { Driving } \\
\text { Condition }\end{array}$ & 30 & 40 & 50 & 60 & 70 & 80 & 90 & 100 & 110 \\
\hline Urban & Local & 4 Levels & & & $\mathrm{x}$ & $\mathrm{x}$ & & & & & \\
\hline Urban & Access - Residential & 4 Levels & $\mathrm{x}$ & $\mathrm{x}$ & $\mathrm{x}$ & & & & & & \\
\hline Urban & City Motorway & 4 Levels & & & & $\mathrm{x}$ & $\mathrm{x}$ & $\mathrm{x}$ & $\mathrm{x}$ & $\mathrm{x}$ & $\mathrm{x}$ \\
\hline
\end{tabular}

2

3

4

Table 2. Sound power levels for cycle $\mathrm{i}$ and cycle ii, corresponding to $V_{\text {limit, }}, V_{\text {mean }}$ and the driving cycle

\begin{tabular}{|c|c|c|c|c|c|c|}
\hline & \multicolumn{3}{|c|}{$\begin{array}{c}\text { Cycle i } \\
\text { City Motorway ; Speed limit }=70 \mathrm{~km} / \mathrm{h} \text {; } \\
\text { Free Flow }\end{array}$} & \multicolumn{3}{|c|}{$\begin{array}{l}\text { Cycle ii } \\
\text { Local ; Speed limit }=50 \mathrm{~km} / \mathrm{h} \text {; } \\
\text { Saturation }\end{array}$} \\
\hline & $V_{\text {limit }}$ & $\begin{array}{c}V_{\text {mean }}= \\
63.6 \mathrm{~km} / \mathrm{h}\end{array}$ & driving cycle & $V_{\text {limit }}$ & $\begin{array}{c}V_{\text {mean }}= \\
20.2 \mathrm{~km} / \mathrm{h}\end{array}$ & driving cycle \\
\hline$L_{\mathrm{rol}, \mathrm{A}}$ & 99.4 & 98.3 & 98.7 & 90.9 & 81.8 & 88 \\
\hline$L_{\text {prop,A }}$ & 91.4 & 91.1 & 91.5 & 85.6 & 86.2 & 87.3 \\
\hline$L_{\mathrm{w}, \mathrm{A}}$ & 100 & 99.1 & 99.5 & 91.9 & 87.5 & 90.7 \\
\hline
\end{tabular}

6

7

8 

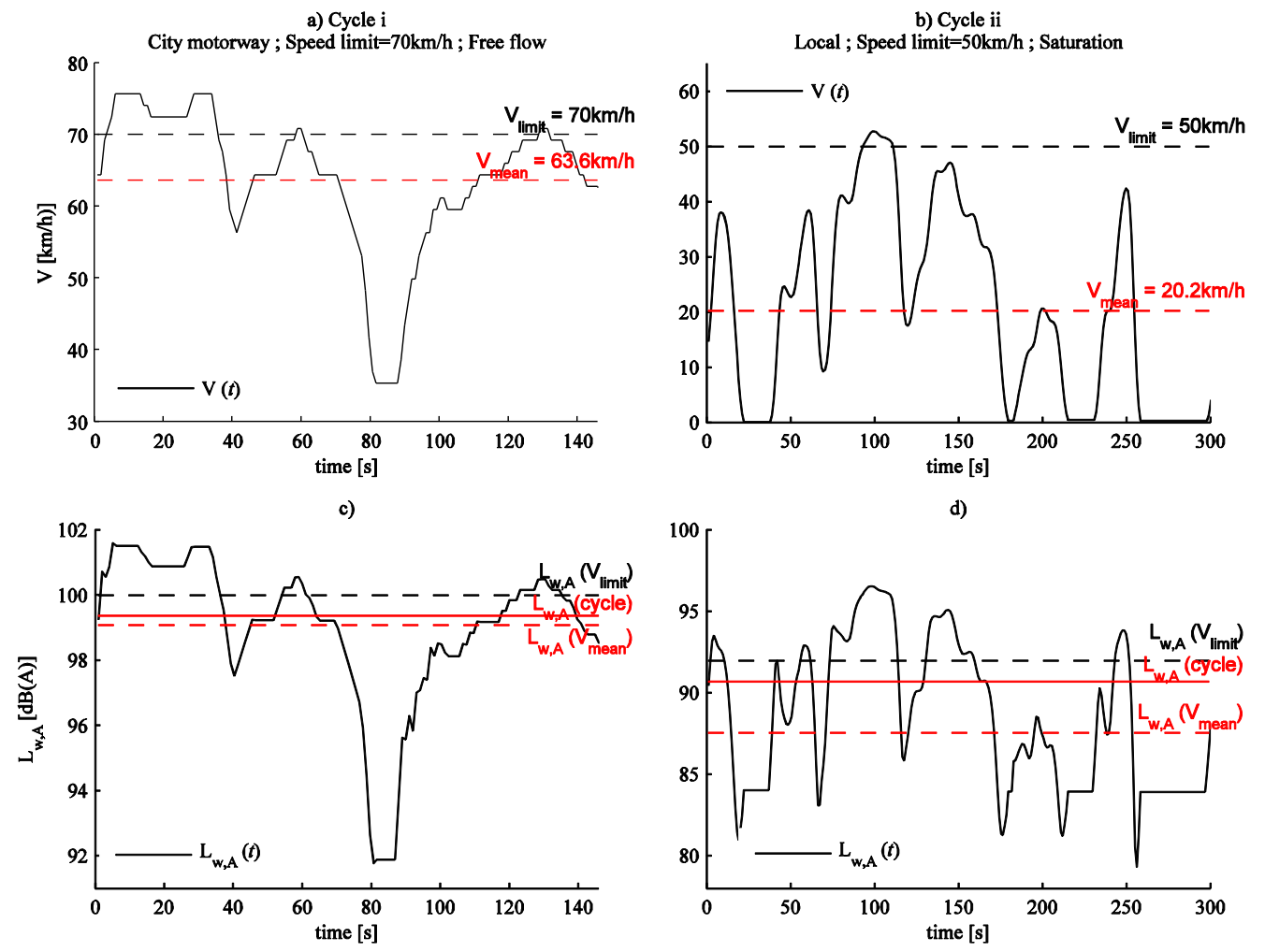
traffic situations 
a)

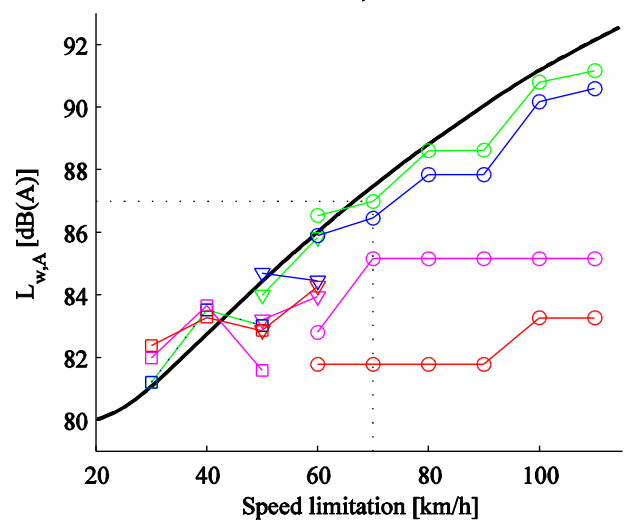

c)

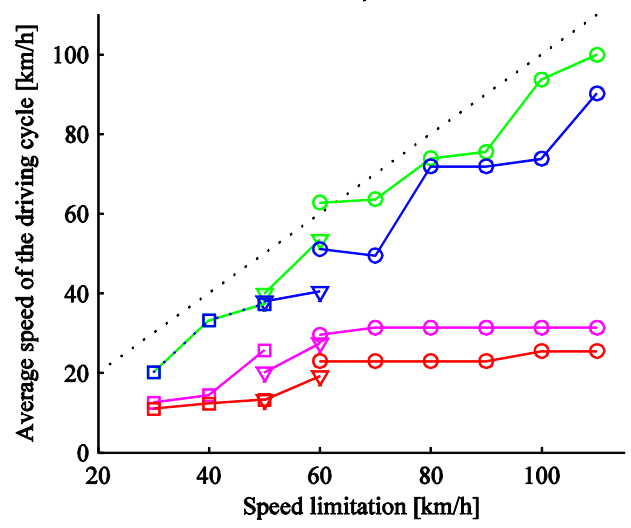

b)

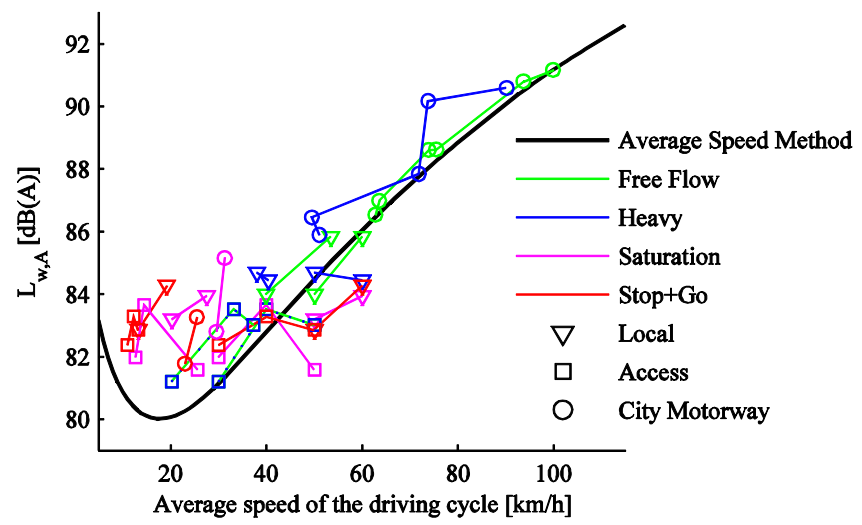

d)

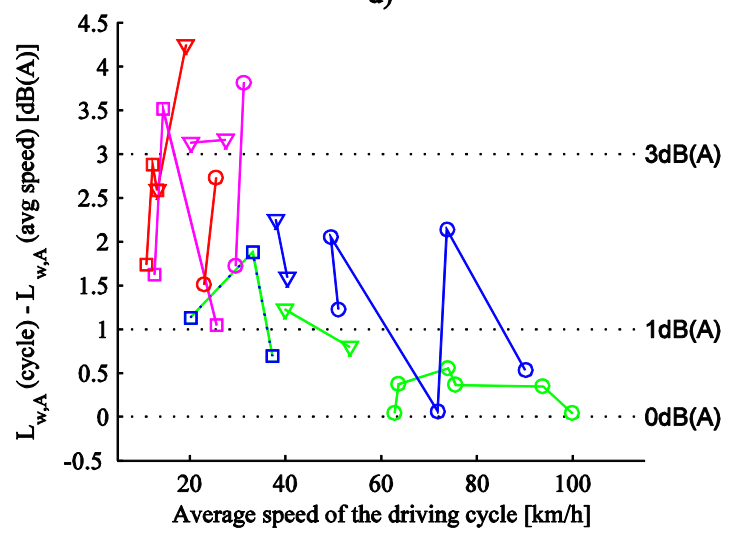


a) Cycle $\mathrm{i}$

City motorway ; Speed limit $=70 \mathrm{~km} / \mathrm{h}$; Free flow

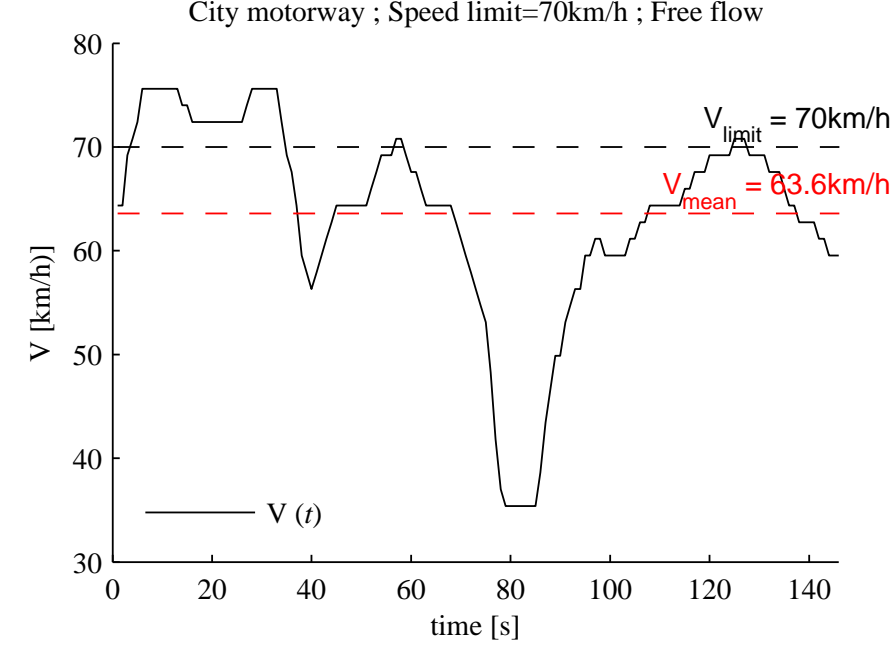

c)

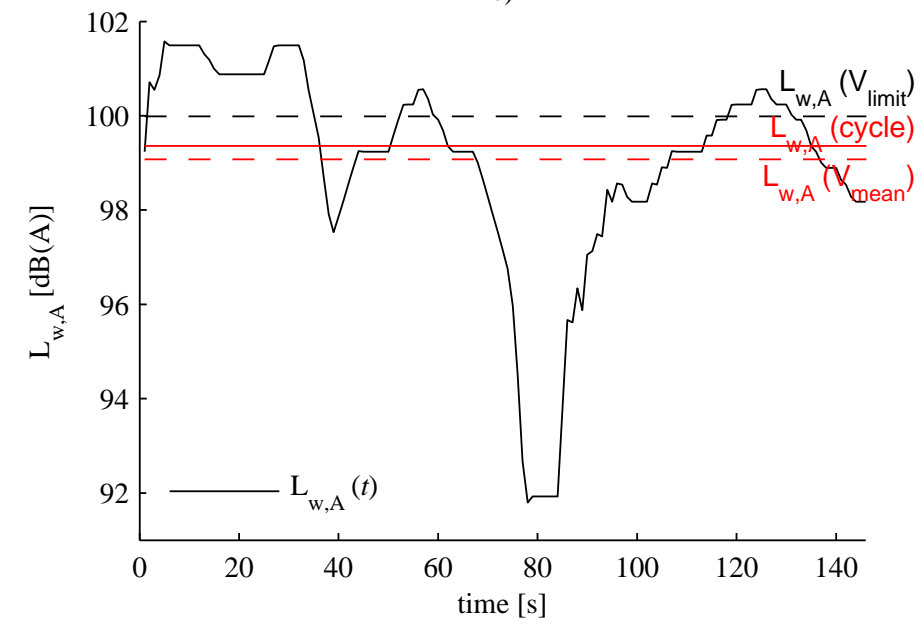

b) Cycle ii

Local ; Speed limit $=50 \mathrm{~km} / \mathrm{h}$; Saturation

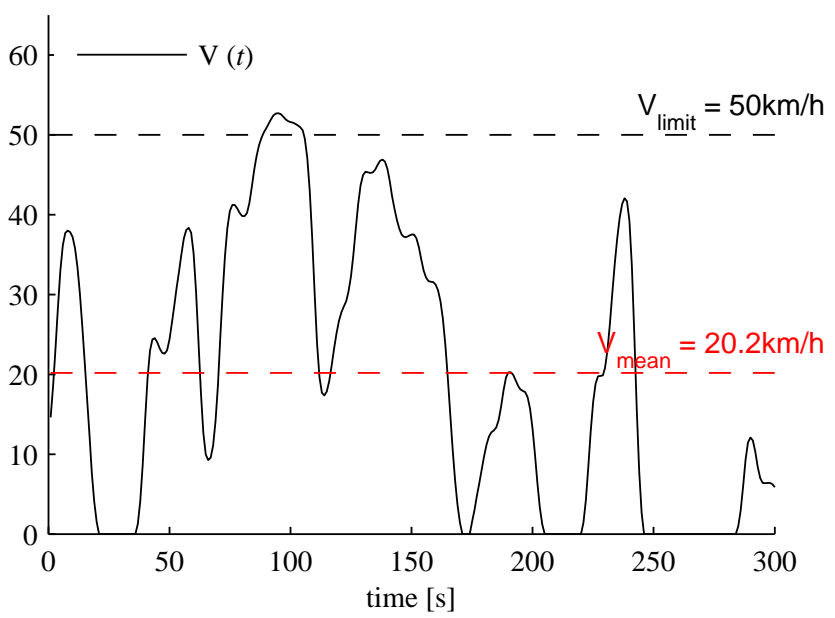

d)

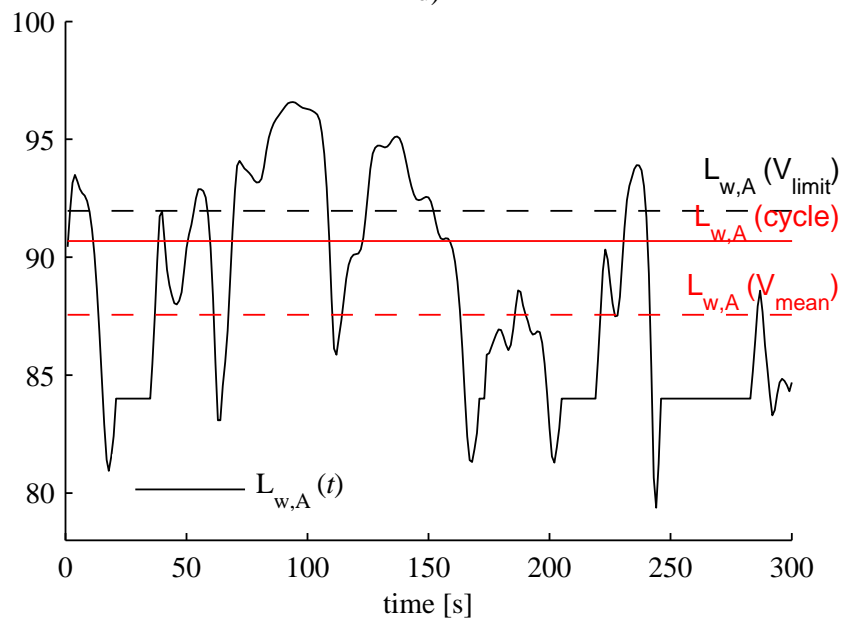


a)

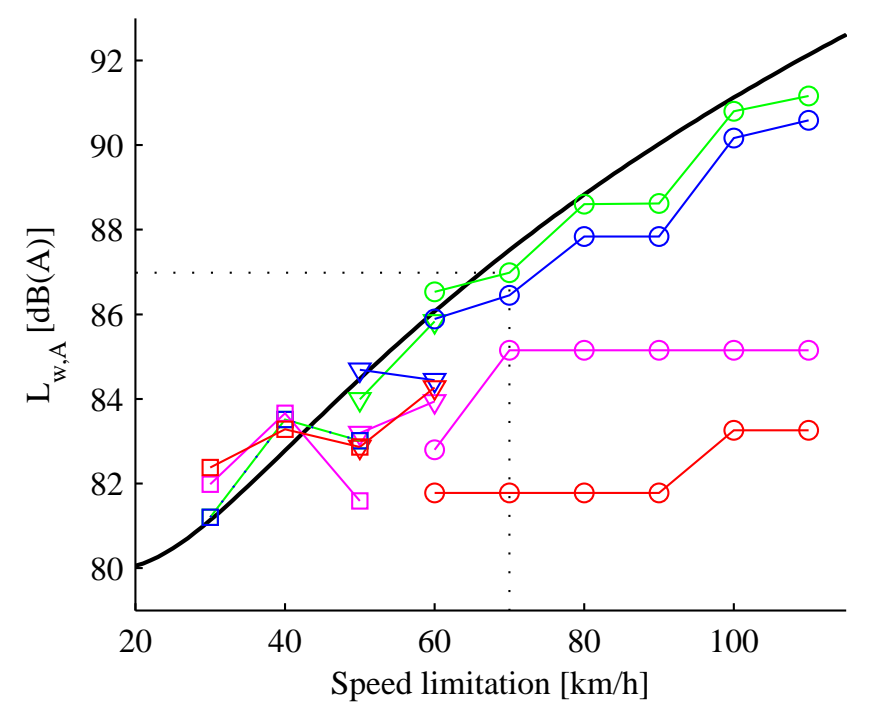

c)

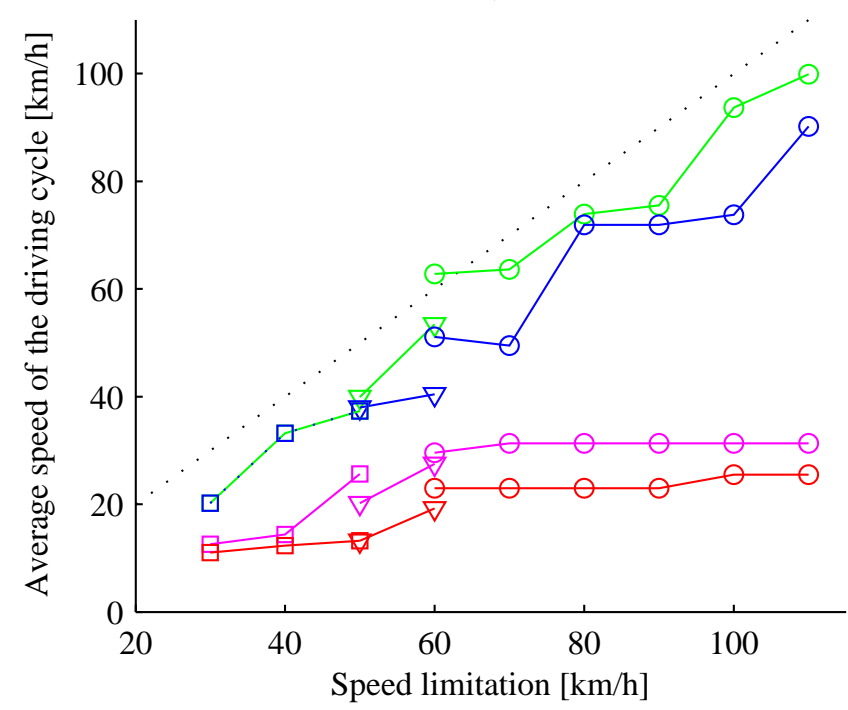

b)

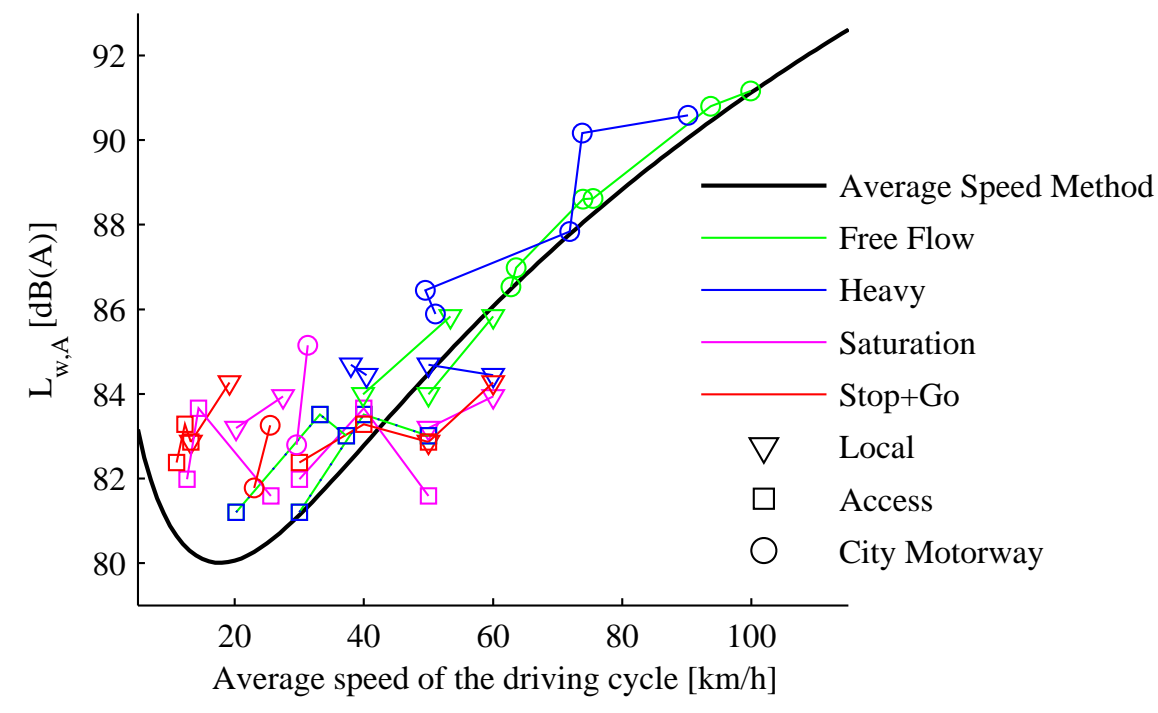

d)

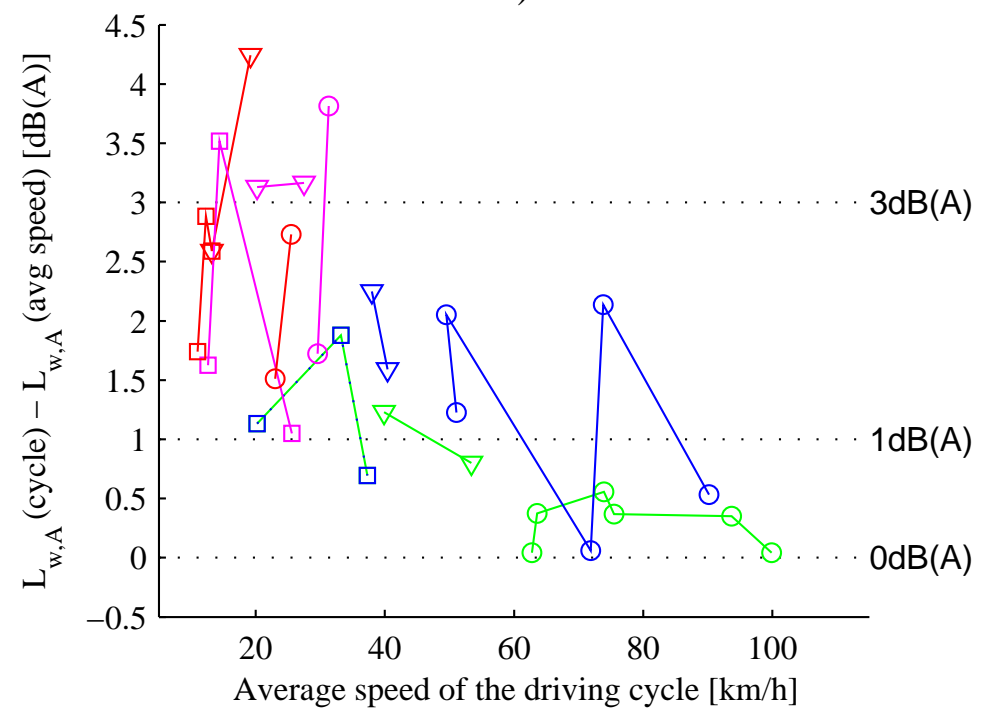

